\title{
Safety Induction Program in Relating of Enhancing Safety Awareness at Construction Site
}

\author{
Siti Zubaidah Hashim, Nadira Ahzahar, Intan Bayani, Zaini Hashim \\ Faculty Architecture, Planning and Surveying, Universiti Teknologi MARA Seri Iskandar Campus, 32610 Perak, Malaysia
}

Correspondence Author: Siti Zubaidah Hashim, Faculty Architecture, Planning and Surveying, Universiti Teknologi MARA Seri Iskandar Campus, 32610 Perak, Malaysia

Received date: 11 April 2018, Accepted date: 25 July 2018, Online date: 8 August 2018

Copyright: (C) 2018 Siti Zubaidah Hashim, et al. This is an open-access article distributed under the terms of the Creative Commons Attribution License, which permits unrestricted use, distribution, and reproduction in any medium, provided the original author and source are credited.

\begin{abstract}
Issues of safety on construction sites is not something new to be discussed in Malaysia. This industry has always contributed to the data in the high-performance workplace accidents rate, as reported by the authorities. Apart from the seriousness of the top management of the employer, health and safety performance also revealed capacity is determined by the workers themselves. In Malaysia, most construction workers are made up of foreigners such as Indonesia, Nepal and Bangladesh. Their large numbers in this sector is not new issues. Government policies relating to this issue is clear and must be adhered to by all parties. Because of safety performance at construction sites also contributed by a foreign force, an effective communication and training is very important to ensure the objective to have safe and conducive workplace achieved. Proactive steps taken by the CIDB to introduce a Green Card Program induction course to all who worked construction site are good. While the provisions of training and disseminating of safety information has clearly stipulated in OSHA 1994 and FMA 1967 and shall be comply by the employers. Besides the induction course is required by the CIDB, most of the companies also have systems that required to conduct safety induction to new employees before their can start with their works. Therefore, this study attempts to peel the extent to which the factors of language, race, duration, content and expertise of trainers that should be considered and has given impact to the program from foreign workers perception. In addition, the effectiveness of the existing system or program must be reviewed by all parties. A comprehensive study should make by all parties, the study should also indivates that the factor discussed is significant to them and will be given significant reasons to determine the effectiveness of the program.
\end{abstract}

Key words: Induction program ·Safety and health·Construction site.

\section{INTRODUCTION}

In Malaysia, construction industries are an important sector of any national economy, especially regarding its employment potential where involvement of local or foreign workers. The past statistic records are shown accidents, incidents, injuries and fatalities continue to occur unabated on constructions site around the world including Malaysia at consistently high rates [3].

The construction industries tend to have a low awareness of the long-term benefits of safety practices, while the tendering process often given little attention to safety and workers selection which is a part of human capital development. The unsatisfactory OSH record of the construction industry has always been highlighted. It is because the OSH management system is a neglected area and a function that has not been pursued systematically in the construction industries.

Safety is an important issue, but many employers do not feel it is vital to the success of companies. Personal factors played a major part leading to accidents. Most construction activities are carried out manually and thus, it makes workers' physical and mental capability an important aspect which will influence their performance in complying with established procedures. The workers involved would normally have to adjust the way of working to suit the features and nature of work requirements. The demanding condition will normally result in awkward body positioning that affects the behavior of workers [2]. When facing obstacles, workers tend to look for a faster and easier way of doing work. This has often leaded to neglecting the safety aspects. This situation is worsening when monitoring by the management is lacking and provision of work facilities is almost non-available.

An important of effective communication to increase workers awareness are not been consider while implementation of Safety Management System totally. High rates of injury are primarily due to inadequate or non-existence of an effective OSH management system. Many occupational accidents and injuries are due to breakdown in the existing OSH communication to the construction workers. Manpower is one of the most pressing challenges facing by the Malaysia Construction Industry as the "Wet Trade" construction approach at present relies heavily on the availability of the large number of foreign labour. Year by year, the increases of labor foreign workers were rapid significantly either legal or illegal from the various country such as Indonesian, Bangladeshi or Vietnamese [6].

The Malaysian Construction Industry has revamped its employment of foreign workers beginning the third quarter of 2002 where the development of property and high demand for better living and business opportunities.

Problem Statement:

In construction industries we are depending with the foreign labour. In the meantime, labour demand has been constantly increasing in the construction sector because the higher tempo of development. Jobs in the Malaysian construction industry are becoming unpopular among the working population in newly industrialized countries as they are more labour intensive, often difficult and to some extent, foreign labour has helped to reduce the shortage of workers in the construction industry.

Consequently, the inflow of the foreign labour into the country served to overcome this labour shortage. Nonetheless, the present influx of foreign labour in recent years, legal and illegal, has created several major issues and implications on the local scenes: economic, social as well as political [1]. 
Some contractors who employ foreign workers, have encountered problems. These problems include:

i. Many workers do not have prior construction experience, thus resulting in low productivity and poor quality of work;

ii. Some of them were not able to cope with the new experience of working on large-scale projects;

iii. Social and cultural problems arising from workers who were coming from a different region;

iv. Training was difficult, as most workers were paid daily wages and were reluctant to undergo training due to loss of pay.

Therefore, it is useful to determine the causes, impacts and ways to minimize the impacts on employing foreign labour Malaysia construction industry. Therefore, efficient and effective OSH management system is essential to be adopted in order to enhance the organization's success. Construction workers at site are among important components in producing products of the construction industry, the safety and health awareness of construction workers are one of the most important concerns of the employer.

A comprehensive and effective consultation and communication mechanisms shall be established while performing project operation. Safety and Health Induction program is a main tool used to induct and train the workers before working at construction site. Communicating and consulting on matters of health \& safety are vital elements in organizing for health and safety [5].

From the records, tables (Table 1.1) below are shown the statistic of accident from Department of Occupational Safety and Health (DOSH) was the result of high rate of accident and fatality.

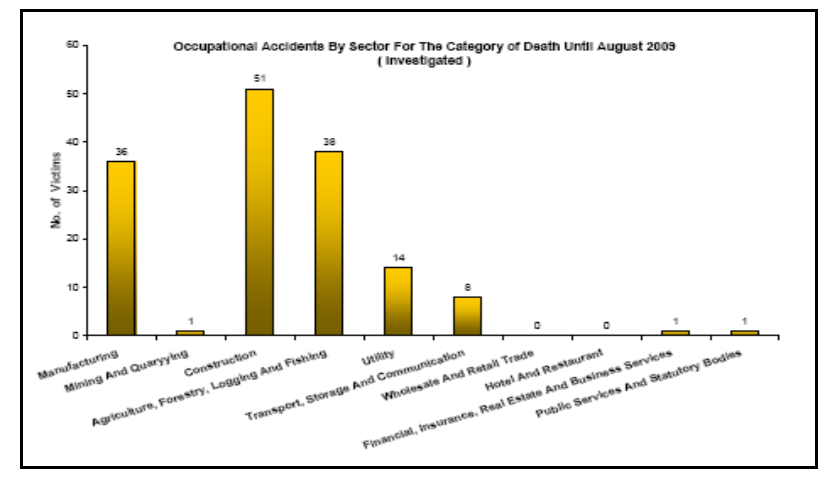

Fig. 1.0: Occupational accident by sector (Death) until August 2009.

\section{Methodology:}

Research Design:

The research methodology is set to gather the data to achieve the outlined objectives. The first step of study is to rationalize the issue to set up the topic of study. Then the statement of problems, aims and objectives were developed. This study employed several methods of data collection to achieve the objectives.

For the knowledge acquisition phase, the literature for this research to be carried out is reviewed through journals, books, conference papers, magazines, and websites from that information, a set of questionnaire form develop. The target respondents are foreign workers from Indonesian, Bangladesh and Vietnam workforce. The data analyzed using statistical method. The final phase of the study is to define the conclusions and recommendation with reference to the objectives, by analyzing of questionnaire.

A primary and secondary data will be used to support the research study were summarized as table below.

Table 1: Research study method.

\begin{tabular}{|l|l|}
\hline Primary survey & Secondary survey \\
\hline Structured Interview/ Questionnaire Survey & Journal, article, website and research paper \\
\hline
\end{tabular}

\section{Survey Population:}

The survey must be conducted at various work projects site under the IJM Corporation Berhad were currently construction progress within $40 \%$ to $60 \%$ of completion. $10 \%$ to $20 \%$ from every races and population of workers (Indonesia, Bangladesh and Myanmar) were selected to complete the research.

\section{Procedures:}

In conducting this research, it uses personal administered questionnaire by asking related questions to respondent. By giving questionnaires, valuable information could be gaining to reach the findings. The function of questionnaire is to give clear definition of the questions, so the respondents will understand what we are trying to ask them, and we will get primary data directly from our respondents.

The questionnaires are divided into 3 sections. It would be as following:

- SECTION A: Demographic questions.

- SECTION B: Respond in the HSE Induction Program.

All demographic variables such as age, gender, marital status, years of service with the company, division and level of designation were tapped under SECTION A by using category scale. The category scale uses multiple items to elicit a single response.

i. Age is important to indicate level of respondent's experience with the Company;

ii. Gender to indicate response rate between male and female respondents;

iii. Marital Status to identify the marital status among respondents;

iv. Years of service the longest period of service will indicate that that respondent had more exposure about safety attitude of employees and workplace safety;

v. Designation will indicate whether respondent is either within management or non-management level.

The thesis is using Likert Scale for all questions of each dimension. The Likert Scale is designed to examine how strongly subjects agree or disagree with statements on a 5-point scale with the following anchors:

Table 2: Linkerd Skill.

\begin{tabular}{|l|l|l|l|l|}
\hline Strongly Disagree & Disagree & Neutral & Agree & Strongly Agree \\
\hline 1 & 2 & 3 & 4 & 5 \\
\hline
\end{tabular}

Each dimension consist 4 questions. Some questions were worded positively, and some were worded negatively. By handling questionnaire, we will encourage the respondent to cooperate and the answers will be treated confidentially. 
Questionnaires that will be given to them are based on the variables. Based on the research objective, 5 factors have been identified for effectiveness of the safety induction program:
i. induction module,
ii. target group
iii. races,
iv. duration of the training,
v. capability of trainer and
vi. languages presentation

The mentioned factor will be an independent variable of the research study as identified figure below.

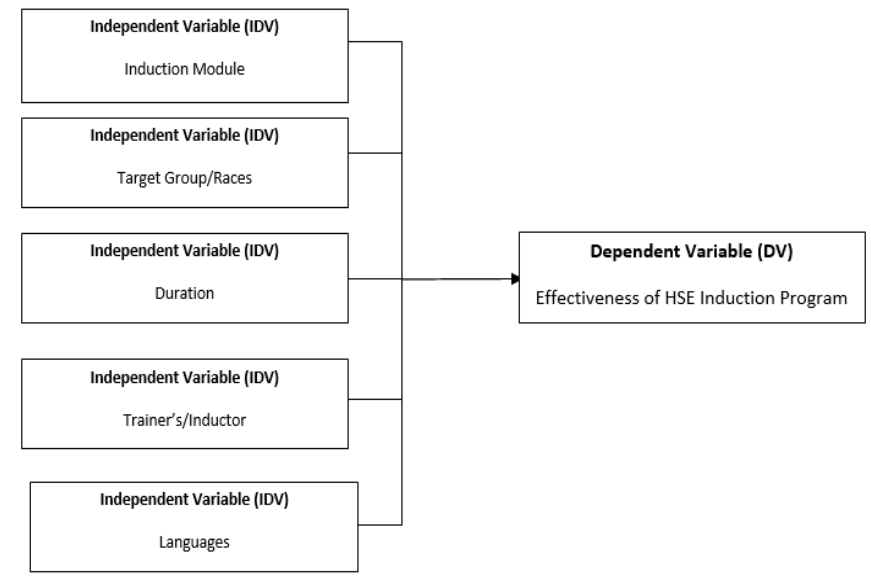

Fig. 2: Independent Variable and Dependent Variable of the research.

Data Collection:

Data analysis and results obtained from the case study that had been carried out. The data from respondents will be process computerized using normal Microsoft excel and pivot application.

Results:

Total Population:

A few projects under IJM Corporation have been selected as workplace sampling where the work progress is between $20 \%$ to $60 \%$ completion. There is no difficulty of getting respondent as planned (by races) at identified project. In total 150 workers has been participate in this survey. Details of number respondent and project involved in this study as tabled below:

Table 3: Sampling Population.

\begin{tabular}{|l|l|l|l|l|}
\hline Project Name & Indonesian & Bangladeshi & Myanmar & Total \\
\hline Grand Hyatt Hotel & 11 & 4 & 2 & 17 \\
\hline The Light Linner & 15 & 4 & 2 & 21 \\
\hline Seremban EDT & 14 & 15 & 1 & 30 \\
\hline Bukit Mandarina & 15 & 4 & 5 & 24 \\
\hline Seremban 2 & 25 & 5 & 3 & 33 \\
\hline Laman Baiduri & 19 & 3 & 3 & 25 \\
\hline & $\mathbf{9 9}$ & $\mathbf{3 5}$ & $\mathbf{1 6}$ & $\mathbf{1 5 0}$ \\
\hline
\end{tabular}

Demographic Analysis Result:

To split the races who participated in this study, there is $66 \%$ of Indonesians, $23 \%$ of the people of Bangladesh and the remaining $10 \%$ of ethnic Myanmar has been involved in this survey as tabled below:

Table 4: Respondent by races tabulation (percentage).

\begin{tabular}{|l|l|l|}
\hline Indonesia & Bangladesh & Myanmar \\
\hline 66.00 & 23.33 & 10.67 \\
\hline
\end{tabular}

For information related to the age (Table 5) of respondents was, majority they are made up of people aged between 25 years to 35 years, that was $54 \%$, then followed by the age of 36 years to 46 years by $23 \%$ and is made up of 24 years and below age of $20 \%$.

Table 5: Respondent ages (percentage).

\begin{tabular}{|l|l|l|l|}
\hline 24 years old and below & Between 25 and 35 years old & Between 36 and 46 years old & Others \\
\hline 20.00 & 54.67 & 23.33 & 2.00 \\
\hline
\end{tabular}

For the breakdown by gender (Table 6), the plumpness of the respondents was male $(92 \% \mathrm{t}$ ) and only $8 \%$ respondent are female.

Table 6: Respondent genders (percentage).

\begin{tabular}{|l|l|}
\hline Male & Female \\
\hline 92.00 & 8.00 \\
\hline
\end{tabular}

Table 7 indicate approximately $82 \%$ of respondents to understand and used Bahasa Malaysia to communicate. There is also a small percentage $(0.6 \%)$ understand English and the rest only know to use the mother tongue of each country which includes $16 \%$. 
Table 7: Languages used for communication (percentage).

\begin{tabular}{|l|l|l|}
\hline English & Malay & Only my country language \\
\hline 0.67 & 82.67 & 16.67 \\
\hline
\end{tabular}

For information on the working experience (Table 8) in construction industries of respondents, 38\% of them have worked between 6 months to 1 year, $34 \%$ is more than one year of experience, and $10 \%$ are experienced only for 1 month to 6 months and the remainder (16\%) less than one year.

Table 8: Years working as construction workers (percentage).

\begin{tabular}{|l|l|l|l|}
\hline Less than 1 month & Between 1 month to 6 months & Between 6 months to 1 year & Above 1 year \\
\hline 16.67 & 10.00 & 38.67 & 34.67 \\
\hline
\end{tabular}

For the questionnaire on duration respondent attended the induction courses, most of them had attended between 1 year (48\%), ranging from 1 year to 3 years (35\%) and within one month of about $16 \%$ as tabled below:

Table 9: Period of attended Induction Program (percentage).

\begin{tabular}{|l|l|l|l|}
\hline Attended between 1 month & Attended between 1 year & Attended 1 to 3 year & Non-attended \\
\hline 16.67 & 48.00 & 35.33 & 0.00 \\
\hline
\end{tabular}

Independent Variable Analysis:

Table 10 indicated the studies to determine the level of acceptance, satisfaction and relevance to their task and safety aspect. The result shows $41 \%$ of respondents strongly agree with the statement, $28 \%$ agree, $18 \%$ natural and the remaining $9 \%$ and $2 \%$ disagree and strongly disagree.

Table 10: Respond from the survey about the program (Percentage).

\begin{tabular}{|l|l|l|l|l|}
\hline Strongly Disagree & Disagree & Natural & Agree & Strongly Agree \\
\hline 2.93 & 9.07 & 18.00 & 28.67 & 41.33 \\
\hline
\end{tabular}

For questions regarding the content of training modules, it includes understanding and objectives of the course, the data received showed a $37 \%$ strongly agree, $30 \%$ agree and $21 \%$ natural, $7 \%$ disagree and $3 \%$ strongly disagree.

Table 11: Respond from the survey about the module/course content (percentage).

\begin{tabular}{|l|l|l|l|l|}
\hline Strongly Disagree & Disagree & Natural & Agree \\
\hline 3.33 & 7.56 & 21.11 & 30.11 \\
\hline
\end{tabular}

For the program duration, respondent also shows that training is not sufficient for a day and exercise should be repeated as often as possible as percentage tabled below.

Table 12: Respond from the survey about the training duration (percentage).

Table 12: Respond from the survey about the training duration (percentage).
\begin{tabular}{|l|l|l|l|l|}
\hline Strongly Disagree & Disagree & Natural & Agree & 16.67 \\
\hline 18.44 & 13.11 & 12.44 & 39.33 \\
\hline
\end{tabular}

Table 13 indicates the language factor; $56 \%$ respondents strongly agree and $20 \%$ agree that country origin language shall be considered and will affect on effectiveness of the induction program.

Table 13: Respond from the survey about the program languages (percentage).

\begin{tabular}{|l|l|l|l|l|}
\hline Strongly Disagree & Disagree & Natural & Agree \\
\hline 0.22 & 4.22 & 17.78 & 20.89 \\
\hline
\end{tabular}

The results clearly show (Refer to Figure 3, Table 4, 7, 10 and 4.13), most of the respondent are strongly agreed with the designed survey question where the races and language been selected as main factor. With that result, it can conclude that there have a significant between background of the workers with the understanding with safety and health system at workplace.

Apart from that, the language used will affect the effectiveness of the unduction program. The other factor that can influence the effectiveness of induction program is competency level of safety inductor personal that should be considered to achieve the objectives of induction program.

Conclusion:

Beside authority body such as DOSH and CIDB, the project owners are equally important in the promotion of safety and health program by including familiarization in workers behavior and background when establish a site safety plan and awareness program.

As part of a good safety and health management system in construction, all level of personnel shall be adequately trained. Contractors should identify and develop general training curriculum/kit for construction workers, which should include but not limited to general awareness, tool-box talks, hazard identification techniques, basic first aid, handling and reporting of accidents, etc. The purpose of the proposed kit is to enable Principal Contractors to organise and conduct onsite training program.

All construction personnel are required to undergo a one-day (minimum six hours) induction course prior to being allowed to work on site. The current program shall be total effectively implemented by the related parties.

The current program did not make any provision for CIDB Green Card holders to undergo a refresher program for renewal. Construction personnel especially foreign workers should be kept refresh and enhance their knowledge on the safety requirement. The employer shall take an initiative to formulate, develop and implement a refresher program for the inducted personnel.

\section{Recommendation:}

The research was found, there are a various area can be improved and considered while discussing on effectiveness of safety induction program. Basically, there is tripartite involvement and participation needed namely the employee (include workers), employer or business owner and government body. Others recommendation for the improvement of the program are as described below.

Compliance to legislation requirements:

Over many years, the Department of Occupational Safety and Health (DOSH) and Construction Industrial Development Board (CIDB) has taken a lot of effort to establish a legislative and work standard to reduce the number of people who are killed, injured, or suffering ill health as a result of construction work. But their initiative alone is insufficient to increase or strengthen safety and health activities within the growing construction industry. Earnest effort from all the industry stakeholders is also necessary. 
Compliance to legislation and management systems put in place by industry players need to be monitored and performance evaluated so as to ensure its effectiveness. Therefore, adequate control and monitoring mechanism must be in place.

Government Regulatory Bodies monitoring the performance of safety and health in the construction industry are expected to exercise their statutory responsibilities. It could be in the form of enforcement or collaboration with other stakeholders in promotional activities, development of training curriculum and standards.

Training and Education:

Education and training is a continuous process for human development, and therefore construction personnel should be equipped with suitable knowledge and skill on occupational safety and health through increasing the number of education and training programs. Training should be extended to all level of workers in the industry.

Among the immediate measures adopted by the CIDB include the introduction of the safety and health induction course for construction workers and occupational safety and health management system course for contractors. Safety Induction program play an important role in reducing accidents. To impart safety and health management skills and to inculcate safe working behaviour amongst workers, a number of safety and health training programs has been identified for implementation. It is envisaged that a strong focus on education and training will afford greater opportunity to all in the industry to relearn and equip them with the knowledge necessary to produce innovative solutions to safety and health issues in the industry.

Promotion of safety and health activities among industry stakeholders is vital. It is envisaged that through aggressive promotion, the safety and health awareness among the construction industry players can be further improved. Promotion programs lined up for implementation include sensitization of prosecutions occupational safety and health management systems, safe work practices.

The industry is also important in terms of employment generation. Despite its important contribution to the nation's economy, the industry is still saddled with serious problems such as low quality, low productivity, poor image, economic volatility, bureaucratic delays, lack of ethics, shortage of skill manpower and lack of data and information [4].

The shortage of skill manpower in the industry is caused by poor industry image, lack of training culture, too many construction activities at one time, and over dependence on labour. Promotions on Occupational Safety \& Health should be one of the main pillars of enhancing safety and health in the construction industry. Promotion activities should be enhanced and aggressively pursued. Stakeholders should be encouraged to organise safety and health promotion activities regularly.

\section{REFERENCES}

[1] Goetsch, D., 2005. Occupational Safety and Health for technologists, engineers and managers (5th ed). Upper SaddleRiver, NJ: Pearson Education, Inc.

[2] Hammer, Willie, 1989. Occupational Safety and Management and Engineering. 4th ed. Prentice Hall, New Jersey.

[3] Ismail, N.H., 1996. Health hazards in the steel mills. In Rampal KG \& Ismail NH (Ed). Occupational safety and health in Malaysia, pp: 108-114. Malaysia:NIOSH.

[4] Jaya, S., 1996. The development of occupational health in the oil industry. In Rampal KG \& Ismail NH (Ed). Occupational safety and health in Malaysia. (pp 43-54). Malaysia:NIOSH.

[5] Marshel, R., 1996. Construction safety. In Rampal KG \& Ismail NH (Ed). Occupational safety and health in Malaysia. (pp 43-54). Malaysia:NIOSH.

[6] Ng, W.K., Maimunah Khalid, 2002. Follow-up Survey of OSH Performance Among Participating Companies in the WISE Project. Buletin NIOSH, 9(3): 7 8 .

[7] Stellman (ED). Encyclopedia of Occupational Health and Safety (4th ed. Vol. 1, pp. 18.2-18.5). Geneva: International Labour Office.

[8] National Institute for Occupational Safety and Health (NIOSH), 2009 Annual Report, Malaysia. 